\title{
Planetário em Realidade Virtual: Uma Ferramenta para Ensino de Astronomia
}

\author{
Anderson dos Santos Ritta \\ Instituto Federal Sul-Rio- \\ Grandense - IFSUL \\ andersonrittal@gmail.com
}

\author{
Luigui Rodrigues Cabral Jorge \\ Instituto Federal Sul-Rio- \\ Grandense - IFSUL \\ luiguircj@gmail.com
}

\author{
M arcelo da Silveira Siedler \\ Instituto Federal Sul-Rio- \\ Grandense- IFSUL \\ siedler@gmail.com
}

\begin{abstract}
Astronomy may be recognized as an interdisciplinary science with great educational potential, but certain content requires specific structures for better learning; In this scenario the use of a computational tool such as virtual reality can contribute to optimize the teaching of this type of content. This paper presents the study on the implementation and use of a virtual planetarium in immersive environment, aiming to evaluate, respectively, familiarity and usability in the use of the tool. Methodologically characterized as qualitative research, the data collection used physical questionnaires applied to student users. The results showed that the developed tool had an excellent evaluation regarding its usability through the results obtained in the SUS questionnaire.
\end{abstract}

\section{RESUMO}

A astronomia pode ser reconhecida como uma ciência interdisciplinar com grande potencial educacional, mas determinados conteúdos demandam estruturas específicas para um melhor aprendizado; nesse cenário o uso de uma ferramenta computacional como a realidade virtual pode contribuir para otimizar o ensino desse tipo de conteúdo. Este artigo apresenta o estudo sobre a implementação e uso de um planetário virtual em ambiente imersivo, tendo como objetivo avaliar, respectivamente, familiaridade e usabilidade no uso da ferramenta. Metodologicamente caracterizado como pesquisa quantitativa, na coleta de dados foram utilizados questionários físicos aplicados aos alunos utilizadores. Os resultados mostraram que a ferramenta desenvolvida teve uma excelente avaliação quanto à sua usabilidade por meio dos resultados obtidos no questionário SUS.

\section{KEYWORDS}

Virtual reality. Astronomy. Teaching. Development.

\section{Introdução}

A astronomia é uma área reconhecida como uma ciência de caráter interdisciplinar, pois interage com vários componentes curriculares, incluindo física, química e geografia, possuindo, assim, um grande potencial educativo. Apesar disso, a astronomia ainda é apenas vagamente abordada dentro das séries iniciais e do ensino fundamental, gerando, por isso, um enorme desconhecimento de conceitos astronômicos básicos.

Como contribuição para o ensino, a utilização dos planetários mostra-se uma alternativa interessante e construtiva das ciências relacionadas ao universo e a origem da vida.

O planetário é um espaço de ensino muito específico; de acordo com [7] planetários são equipamentos didáticos proeminentes; reproduzem o céu visto em qualquer latitude, mostram de forma precisa as posições do Sol, da Lua e dos planetas em qualquer época. Apesar de, em grande parte, os planetários atuais se constituírem em locais de entretenimento, o principal objetivo desses espaços deve ser atuar como uma ferramenta para o ensino de ciências, mais precisamente a astronomia [7] e [1].

Pensando nos diversos obstáculos que impedem o uso frequente de um planetário, por parte de professores e alunos, com finalidade de ensino, a tecnologia VR (virtual reality) surge como uma ferramenta inovadora que apresenta uma perspectiva diferente na forma de transmitir informações. A tecnologia VR utiliza recursos gráficos $3 \mathrm{D}$ ou imagens em $360^{\circ}$ para criar um ambiente imersivo e totalmente virtual - comumente chamado de Realidade Virtual (RV).

Assim, o presente artigo apresenta o estudo sobre a implementação e uso de um planetário virtual em ambiente imersivo, tendo como objetivo avaliar, respectivamente, familiaridade e usabilidade no uso da ferramenta.

O software em questão busca prover um auxílio ao ensino de astronomia nas escolas e que promova uma forma de aprendizado imersiva, interativa e intuitiva para os estudantes. Dessa forma, o presente trabalho está estruturado da seguinte forma: na seção Material e Métodos são abordadas a modelagem e implementação do software; englobando a seção de Testes de usabilidade e familiaridade da tecnologia; a seção de Análise dos Resultados proveniente das aplicação; Considerações Finais; e por fim as Referências.

\section{Metodologia e Desenvolvimento}


A elaboração desta pesquisa, de cunho quantitativo, envolve as seguintes etapas: desenvolvimento, onde são realizadas a modelagem e implementação do software; uso do software por parte dos voluntários; coleta dos dados através dos questionários, tabulação dos dados e análise dos resultados.

Este trabalho foi desenvolvido em uma parceria entre o IFSul e a Unipampa, instituição que conta com um planetário físico e que busca ferramentas para difundir a astronomia na comunidade. Dessa parceria surgiu a ideia de criar aplicativos voltados para a astronomia e que possam ser levados para a comunidade escolar da região.

Desse objetivo inicial foi prospectado um aplicativo que deveria apresentar o sistema solar, permitindo a interação do usuário de forma imersiva e apresentando as informações gerais de cada planeta.

A partir desses requisitos foi projetado e implementado um aplicativo que simula um planetário usando realidade virtual, apresentando ao usuário o sistema solar, com os planetas que compõe o sistema, respeitando as características de proporção, distância para sol, rotação e translação.

A interação com o usuário ocorre através do uso do óculos VR e um controle auxiliar. O usuário é convidado a imergir no sistema solar, podendo navegar entre os planetas e obter informações de cada um dos elementos apresentados na cena, conforme Figura 1.

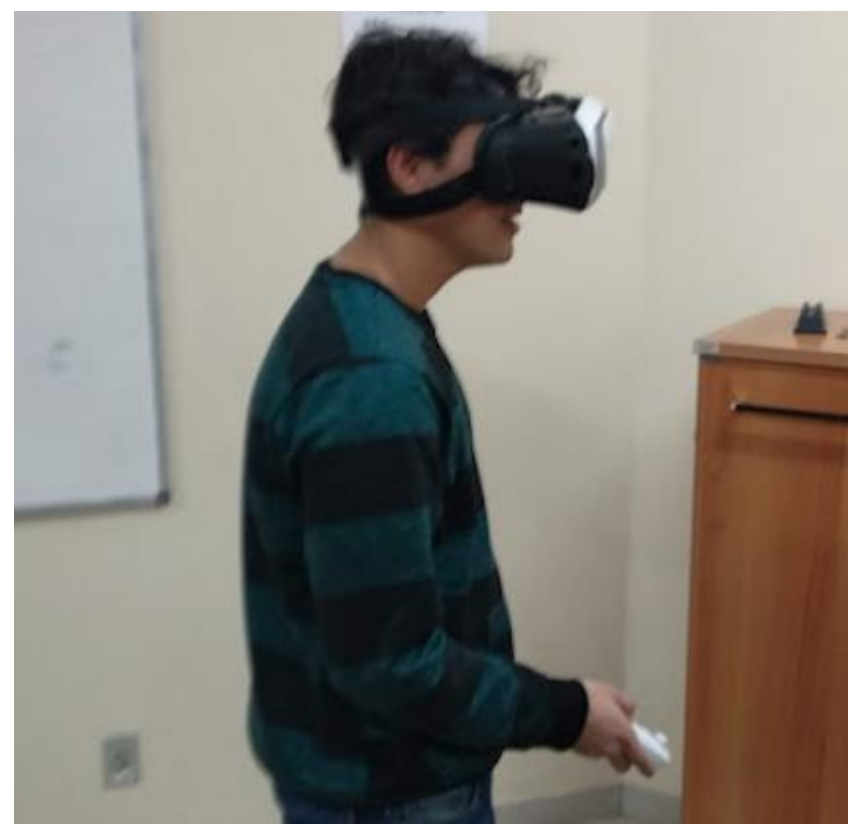

\section{Figura 1: Aluno utilizando óculo VR com o software de planetário virtual}

A interação funciona da seguinte forma: o usuário pode movimentar-se em direção ao planeta desejado e, apenas apertando um botão do controle, consegue visualizar e obter as informações sobre o planeta que ele está olhando no momento do clique. O aplicativo foi desenvolvido a partir da engine Unity, fazendo uso da licença gratuita para estudantes, e codificado com a linguagem C\#. A seguir é apresentado o processo de desenvolvimento do aplicativo.

\subsection{Modelagem}

Para a criação dos objetos do jogo foi utilizado como referência o repositório de imagens, texturas e dados da NASA (National Aeronautics and Space Administration) e, a partir da coleta de informações referentes a cada planeta do sistema solar, iniciou-se a modelagem dos elementos presentes utilizando o software Autodesk 3D Max.

Nesta etapa foram realizadas a edição de texturas, modelagem das formas e transformação de tamanhos para tornar os elementos em escala proporcional a real.

As principais dificuldades encontradas nesta etapa foram, inicialmente, o ajuste fino das texturas dos planetas, haja vista que a inserção precisa manter o posicionamento correto de cada parte dos planetas. Em específico, os anéis de Saturno exigiram um estudo mais aprofundado sobre seu posicionamento real.

\subsection{Implementação}

As primeiras rotinas desenvolvidas foram para executar os movimentos de rotação e translação dos planetas e, posteriormente, a implementação dos módulos de Realidade Virtual utilizando óculos VR. O modelo utilizado foi o VR BOX 2.0 com controle bluetooth auxiliar, com regulagem de tamanho e ajuste de foco. Logo após, ajustando as especificações de cada planeta isoladamente, formando por fim o sistema solar representado de forma simulada no ambiente do aplicativo(Figura 2).

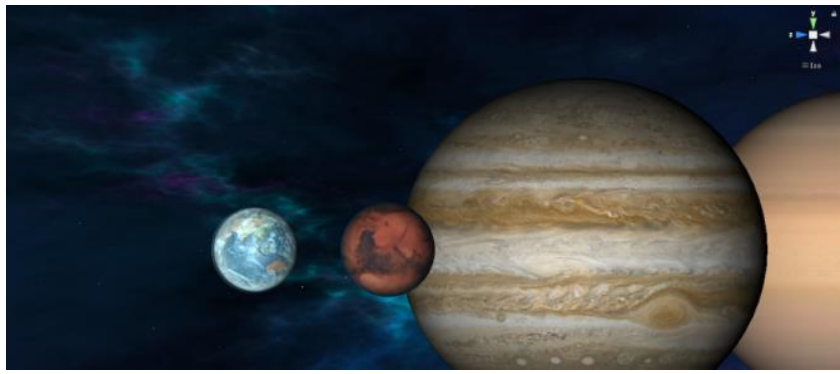

\section{Figura 2: Representação do sistema solar na plataforma} Unity

Com os planetas criados e alinhados, implementou-se a interação do usuário através do uso de um controle que permite interagir com o ambiente de realidade virtual, interagindo com os elementos 
A implementação da interação do controle com os elementos da tela foi uma das etapas mais difíceis do processo de desenvolvimento do trabalho. A identificação dos botões clicados, a delimitação da área de clique e o comportamento que o aplicativo deve ter quando acionado o botão foram tarefas complexas, além dos testes serem custosos, pois exige que o aplicativo seja executado no celular para que o controle o óculos possam ser usados(no Unity a execução é simulada, e o clique do mouse não corresponde, necessariamente, ao comportamento do controle).

A versão atual do aplicativo está totalmente funcional e sendo colocada em testes nas escolas da rede pública. A seção a seguir apresenta o teste de usabilidade do aplicado desenvolvido.

\section{Teste de Usabilidade e A nálise dos Resultados}

Para validar o aplicativo foram aplicados dois questionários a cada usuário, sendo o primeiro um formulário para medir o grau de familiaridade com a realidade virtual, e o segundo, aplicado após a utilização do aplicativo, para testar a usabilidade do sistema desenvolvido.

De acordo com [5], usabilidade é um conceito chave na interação homem computador e enfatiza a preocupação em fazer sistemas que apresentem facilidade de aprendizagem e na utilização. Para a norma NBR ISO 9241-11, a usabilidade é considerada como sendo a medida na qual um produto pode ser usado por usuários específicos para alcançar objetivos específicos com eficácia, eficiência e satisfação em um contexto específico de uso [4].

Para a compreensão deste conceito torna-se necessário o conhecimento de outras definições apresentadas na NBR ISO 9241-11:

a) Eficácia: acurácia e completude com as quais usuários alcançam objetivos específicos.

b) Eficiência: recursos gastos em relação à acurácia e abrangência com as quais usuários atingem objetivos.

c) Satisfação: ausência do desconforto e presença de atitudes positivas para com o uso de um produto.

d) Contexto de uso: usuários, tarefas, equipamento (hardware, software e materiais), e o ambiente físico e social no qual um produto é usado.

e) Sistema de trabalho: sistema, composto de usuários, equipamento, tarefas e o ambiente físico e social, com o propósito de alcançar objetivos específicos.

A seguir são apresentados os dois questionários aplicados para validar o trabalho.

\subsection{Análise de Familiaridade}

Este questionário, como dito anteriormente, foi aplicado antes do usuário utilizar o aplicativo, e é formado por três perguntas que têm como objetivo obter noções da familiaridade prévia do usuário com a realidade virtual, e foi elaborado com três questões: Já ouviu falar de Realidade Virtual (VR)? - Sim ou Não; Já utilizou algum aplicativo com óculos VR? - Sim ou Não; Se sim, como classificaria a experiência? - Excelente, muito boa, regular, ruim ou muito ruim.

\subsection{Avaliação de usabilidade}

Para testar a usabilidade do sistema desenvolvido foi utilizada a escala System Usability Scale (SUS). A escala SUS é uma tecnologia independente, já tendo sido usada em testes de hardware, software, entre outros, formada por um questionário com

10 itens e cinco opções de respostas [6]. A elaboração do questionário SUS é realizado utilizando a escala Likert que varia de discordo totalmente a concordo totalmente, apresentando cinco opções numéricas de resposta ao usuário, indo de 1, discordo totalmente, até 5 , concordo totalmente.

O SUS produz um único número que representa uma medida composta da usabilidade geral do sistema que está sendo testado. Para calcular a pontuação obtida no questionário basta, para as perguntas de números ímpares, subtrair 1 do número que o usuário marcou como resposta. Para os números pares, a contagem é feita subtraindo de 5 o número marcado na resposta. Feito isso, devese somar as pontuações de cada item e, por fim, multiplicar a soma por 2,5. O resultado obtido será o valor global da escala de usabilidade.

O questionário original foi desenvolvido em inglês e a versão utilizada é variação da tradução realizada no trabalho “ Avaliação de Ambiente Virtual de Aprendizagem com o uso do SUS - System Usability Scale" [2].

\subsection{Aplicação e Análise dos Resultados}

Os questionários foram aplicados a 21 voluntários que utilizaram o aplicativo pela primeira vez. O processo de testes consistiu em, respectivamente, responder o questionário de familiaridade, fazer uso da aplicação e, por fim, responder o questionário de usabilidade.

Considerando o questionário de análise de familiaridade, do total de respostas obtidas apenas um voluntário apontou que não sabia o que é Realidade Virtual e 38\% dos usuários tinha utilizado óculos VR antes de testar o aplicativo e 75\% dos voluntários consideraram a experiência anterior com VR excelente ou muito boa.

No questionário de usabilidade foi medido o grau de satisfação dos voluntários com a aplicação. O questionário consistiu em 10 perguntas e contou com a participação de 21 voluntários que nunca haviam utilizado a aplicação testada. A figura 3 apresenta um gráfico com a apresentação da análise dos resultados obtidos. 


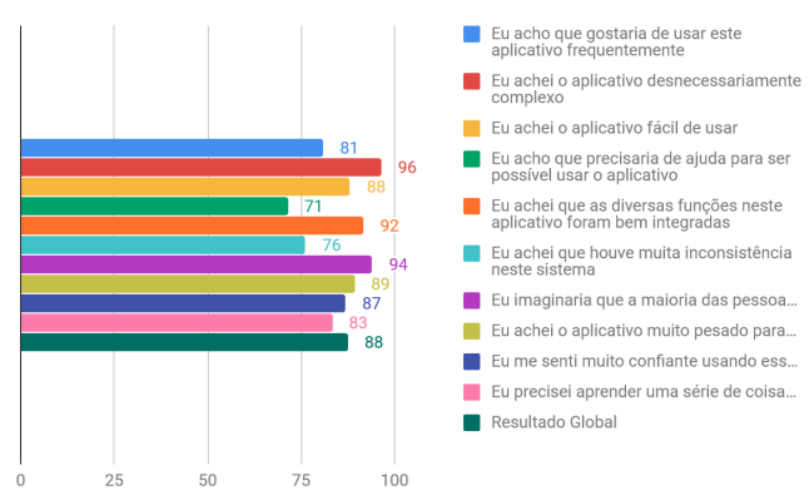

Figura 3: Gráfico com a análise dos resultados das respostas do usuário

Considerando que a escala SUS tem média global de 68 pontos, é possível afirmar que o resultado final dessa avaliação pode ser considerada excelente, haja vista que a pontuação atingida foi de 87 pontos.

Para fins de uma análise mais detalhada sobre cada pergunta do questionário SUS, foi feita também uma verificação do resultado de cada resposta dos usuários, e, com isso, foi possível verificar que em todas as perguntas a aplicação conseguiu superar a pontuação média da escala SUS.

\section{Considerações Finais}

A partir das informações explanadas neste artigo é possível verificar que o Planetário em Realidade Virtual consegue corrigir ou, ao menos, amenizar os problemas que fazem com que a Astronomia não seja amplamente abordada dentro do currículo escolar. Assim como, através de testes, é possível afirmar que essa ferramenta tem uma excelente avaliação quanto a sua usabilidade, pois apresenta resultados bastante positivos no questionário SUS.

Com base em estudos e previsões realizadas pela fornecedora global de inteligência de mercado IDC Corporate - uma subsidiária do International Data Group (IDG) - estima-se que a realidade virtual terá um crescimento de 78,3\% nos próximos cinco anos, puxado principalmente pela educação, tanto no ensino fundamental quanto no ensino superior [3]. É com base nesse crescimento futuro e para solucionar problemas presentes que o Planetário em Realidade virtual se apresenta como uma ferramenta inovadora que consegue alinhar a educação e a realidade virtual dentro de uma mesma aplicação.

\section{REFERENNCIAS}

[1] Andrade, P. A Museabilidade e a Literacia da Ciência: consumos, cidadania e cultura. (Org). Museus Públicos e Literária Científico-Tecnológica. Lisboa: Edições Colibri, 2010. p. 33-50.
[2] Boucinha, R. M.; Tarouco, L. M. R. Avaliação de Ambiente Virtual de Aprendizagem com o uso do SUS - System Usability Scale. 2013.

[3] IDC Tracker. Worldwide Semiannual Augmented and Virtual Reality pending Guide. URL: https://www.idc.com/tracker/showproductinfo.jsp? prod_id=1381.

[4] Milani, F.; Marchi, A. C. B.; Rieder, R. Usability Guidelines to Develop GestureBased Serious Games for Health: a systematic review. 2017 19th Symposium on Virtual and Augmented Reality, 2017. [ONLINE]. Disponível em: https:// conferences.computer.org/svr/2017/papers/3588a188.pdf. Acessado em 11 de julho de 2019.

[5] Preece, J. et al. A Guide to Usability: human factors in computing. Reino Unido: Addison Wesley, 1993. 144p.

[6] Sauro, J. Measuring Usability With The System Usability Scale(SUS). 2009. Disponivel em: http://www.measuringusability.com/sus.php. Acessado em 18 de agosto de 2019.

[7] Steffani, Maria Helena; Vieira, Fernando. Planetários. In: Matsuura, Oscar. História da Astronomia no Brasil. Volume II. MAST/MCTI, Recife: Cepe Editora e Secretaria da Ciência e Tecnologia de Pernambuco, 2014. p.400-418. Disponível em: http://www.mast.br/HAB2013/index.html. Acessado em 3 de julho de 2019. 